\title{
Cannulation strategies in type A aortic dissection: a novel insight narrative review
}

\author{
Qingping Xia ${ }^{1 \#}$, Yong Cao ${ }^{2 \#}$, Baodong $\mathrm{Xie}^{3}$, Dongyun $\mathrm{Qiu}^{3}$, Li Deng ${ }^{2,3}$, Maosheng Wang ${ }^{2}$, \\ Hongguang $\mathrm{Han}^{4}$
}

${ }^{1}$ Department of Science and Education, The People's Hospital of Gaozhou, Gaozhou, China; ${ }^{2}$ Department of Cardiovascular Surgery, The People's Hospital of Gaozhou, Gaozhou, China; ${ }^{3}$ Department of Cardiovascular Surgery, The First Affiliated Hospital of Harbin Medical University, Harbin, China; ${ }^{4}$ Department of Cardiovascular Surgery, The General Hospital of Northern Theater Command, Shenyang, China

Contributions: (I) Conception and design: Q Xia, M Wang; (II) Administrative support: L Deng; (III) Provision of study materials or patients: Y Cao, B Xie; (IV) Collection and assembly of data: Q Xia, D Qiu; (V) Data analysis and interpretation: H Han; (VI) Manuscript writing: All authors; (VII) Final approval of manuscript: All authors.

\#These authors contributed equally to this work.

Correspondence to: Li Deng, PhD. Department of Cardiovascular Surgery, The People‘s Hospital of Gaozhou, Gaozhou 525200, China. Email: dengli_198118@163.com; Hongguang Han, PhD. Department of Cardiovascular Surgery, The General Hospital of Northern Theater Command, Shenyang 110015, China. Email: 13309883275@163.com.

\begin{abstract}
This review highlights vital details that can be easily overlooked and discuss how to identify and fix failed cannulation from another novel insight. Appropriate arterial cannulation strategy during cardiopulmonary bypass (CPB) in Stanford type A aortic dissection (AAD) is highly necessary to reach satisfactory perfusion effects and appreciable clinical outcomes. Despite several previously published reviews on cannulation strategies in $\mathrm{AAD}$, most focus on the advantages and disadvantages by comparing various cannulation strategies. In fact, most of evidence came from retrospective studies. More importantly, however, some important details and novel approaches maybe overlooked due to variety reasons. These overlooked details also make sense in clinical practice. Papers related to cannulation refer to type AAD were retrieved and analyzed from the PubMed and Medline database. The key words such as "aortic dissection", "cannula", "cannulation", “cannulation strategy", “cerebral perfusion”, "type I aortic dissection” were conducted and analyzed. In addition, we looked at some new and very significant specific perfusion techniques such as anterograde cerebral perfusion combined with retrograde inferior vena caval perfusion (RIVP) and reperfusion via the right carotid artery before surgery. The arterial cannulation site and strategy should be determined individually. Monitoring measures are very necessary in the whole procedure.
\end{abstract}

Keywords: Aortic dissection; cannula; anterograde cerebral perfusion; malperfusion; cerebral oxygen saturation

Submitted Feb 11, 2021. Accepted for publication Apr 21, 2021.

doi: $10.21037 /$ jtd-21-411

View this article at: http://dx.doi.org/10.21037/jtd-21-411

\section{Introduction}

Cardiopulmonary bypass (CPB) is essential for treating patients with Stanford type A aortic dissection (AAD) (1). Although different cannulation strategies were adopted based on the surgeon's preference, skill, and patient's anatomical characteristics, along with several successful cases, the controversy regarding how to select an optimal cannulation strategy, which can ensure good organ perfusion and reduce the risk of malperfusion (2), continued to exist (3). None of the existing cannulation strategies was perfect and without complications (4); each cannulation strategy was associated with different advantages and disadvantages owed to varying anatomical characteristics and flow patterns inside the aorta during CPB (5). Also, the situation becomes complicated when dissection develops 
and something unexpected happens during the surgery. Therefore, it is necessary to assess each AAD patient and develop a suitable cannulation plan to obtain optimal perfusion. Although some literature significantly discusses the different cannulation methods in TAAD, no article fully summarized the cannulation methods, and neglected technologies and experiences still exist because of a lack of prompt updates and summary. This review summarized the advantages and disadvantages of different cannulation strategies in AAD and showed the techniques to fix failed cannulation. We have also emphasized vital details that have received limited attention in the literature. We present the following article in accordance with the Narrative Review reporting checklist (available at http://dx.doi.org/10.21037/ jtd-21-411).

\section{Ascending aorta cannulation (AAC)}

Despite several AAC reports stating that it is safe and effective $(6,7)$, performing cannulation in ascending aorta and aortic arch remains a huge challenge.

Proponents believe that this method can achieve anterograde perfusion and is easy to operate (3), but opponents argue that this method's potential risks are significantly high. This approach's main risk is that it may lead to further dissection or rupture of the aortic wall at the insertion site (7). Also, this procedure may cause critical organ malperfusion, such as brain malperfusion, if the cannula is inserted into the false lumen. In general, AAC needs the inclusion of sufficient normal arterial walls for insertion. Therefore, it is important to find and identify normal aortic wall tissues if AAC is used. Frederick et al. (8) reported three dissection anatomy in terms of the relationship of true and false lumens in the ascending aorta and how color can be used to distinguish the true lumen (the color of the vessel wall will be normal red) from the false lumen (the color of the vessel wall will be purple). Complex anatomy lesions increase the difficulty of cannulation, especially in $360^{\circ}$ dissection. Preoperative computed tomography angiography (CTA) and intraoperative transesophageal echocardiography (TEE) can be used to identify the location of true lumen for cannulation (9). A needle was punctured into the true lumen, and a wire was then passed through it. This kind of Seldinger technique guided via intraoperative TEE is necessary for placing the cannula into the true lumen $(10,11)$. Taguchi et al. (10) focused on practical skills, precautions, and pitfalls in the Seldinger technique. It emphasized that the ascending aortic cannula must be inserted significantly deep to place the tip in the aortic arch, especially in cases with a short ascending aorta. Also, as a bridge, safe femoral cannulation before AAC has been described by some researchers to reduce the risk of being fragile in the cannulation site of ascending aorta wall (12). If AAC fails, femoral artery cannulation is used as an alternative strategy to ensure safe surgery.

AAC is not suitable for circumferential dissection or almost circumferential dissection of ascending aorta. For such complicated cases, direct true lumen cannulation can be used (13), during which it is essential to know when inserting the cannula into the false lumen occurs. When the cannula is inserted into the false lumen, there will be a sudden rise in the pump pressure beyond the normal value after the start of CPB. Further, there will be a difference of more than $10 \%$ or a straight drop in $\mathrm{rSO}_{2}$ (14). Also, the pressure difference between the left and right radial artery will be above $20 \mathrm{mmHg}$ (15). If cannula insertion into the false lumen occurs, the aortic vessel's intima should be incised, and the cannula will be inserted into the true lumen under direct vision. If the failure occurs again, AAC can be converted to a femoral artery cannula.

\section{Direct true lumen cannulation (DTLC)}

DTLC is a true alternative lumen and antegrade perfusion technique used for patients who have failed AAC (16). Jakob et al. (17) described this technique as the venous blood being drained into the $\mathrm{CPB}$ reservoir until the systolic blood pressure dropped below $30 \mathrm{mmHg}$. The ascending aorta was transected, and the true lumen was identified, and then the cannula was inserted with direct vision. Finally, the cannula was secured with the previously placed tape, and CPB was started. In another report, Kitamura et al. chose a cannula with a bump and double tourniquet tape for cannulation (13). It is worth noting that they could complete cannulation within three min, and this technique is universally applicable to circumferential dissection or thrombosed ascending false lumen. These authors also mentioned that care should be taken to drop any clots into the true lumen when the ascending false lumen is thrombosed. Conzelmann et al. (18) shared a similar DTLC technique and regarded it as a 'bail-out' strategy when peripheral cannulation failed and 360-degree circumferential separation of the lumen occurred. Meanwhile, they highlighted the Overholt clamp placement behind the dissected aorta as the part of DTLC with the most significant amount of risk, although the adventitial 
layer was carefully separated and kept intact with the ascending aorta and pulmonary artery.

\section{Transapical aortic cannulation (TAC)}

Though the TAC method sounds dangerous and challenging to implement, many surgeons still consider it an excellent choice. Moreover, some surgeons declare that this technique could be achieved rapidly and safely and is easy to learn (19). Meanwhile, TAC can provide enough antegrade flow and secure true lumen perfusion $(20,21)$. This technique continues to be widely accepted. Sosnowski et al. (18) shared their surgical experience in detail. It is worth noting that the authors used a long arterial cannula (30.5 $\mathrm{cm}$ long and wire-reinforced to prevent kinking) to make sure that the arterial cannula passed through the apex of the left ventricle and that the aortic valve lay in the sinus of Valsalva. Moreover, the authors stated that no CPBrelated adverse clinical outcomes were noted even if the cannula was in the left ventricular outflow tract instead of in the sinus of Valsalva. Also, TEE supervision guidance during the TAC procedure is essential. Although some authors thought TAC caused hemodynamic instability due to hypotension and arrhythmia, it may confer a risk of delayed stroke. Hence, TAC with right axillary cannulation as an alternative was used to reduce mortality and morbidity owing to malperfusion risk (22). Indeed, owing to TAC's ability to provide sufficient antegrade aortic flow and secure true lumen perfusion, malperfusion, and cerebral complications could be prevented (23-25). Moreover, no serious postoperative complications occurred, including pseudoaneurysm formation, left ventricle asynergy, and aortic valve regurgitation after surgery at the cannulation site (26). Hence, TAC was a safe method, especially in patients with diffuse atherosclerosis (27). However, TAC is not recommended for patients with aortic stenosis, re-operation, and pericarditis (28). On the other hand, Augoustides et al. (29) still had certain doubts about this method. They hypothesized that aortic valve regurgitation would cause blood to flow into the left ventricle in a retrograde way, which may result in insufficient forward blood flow perfusion and other lead to ischemia of vital organs, left ventricular dilatation with inadequate myocardial protection, and excessive left ventricular reflux. The disadvantage of TAC is that it does not clamp the ascending aorta during cooling, leading to loss of operating time, which can elongate the $\mathrm{CPB}$ time and increase the risk of complications.

\section{Innominate artery cannulation (IAC)}

IAC is one of the most widely used methods in AAD (30). Some surgeons prefer IAC to other methods owing to its time-saving, easy, and reliable method in emergency cases where CPB needs to be quickly established (31-33). IAC cannulation has two methods: a side-arm graft $(8-10 \mathrm{~mm})$ technique, which is connected to a size of 20-22 French arterial cannula (34), and direct cannulation (the outlet of the cannulation facing to the aorta) with a size of 22-24 French cannula connected (35). Although some surgeons favor this method, Ji et al. still believed that there is a potential risk when IAC is used to perfuse the brain. The main reason behind this could be that the blood flow distribution may depend on the resistance of the right axillary artery and left common carotid artery (CCA) when IAC is used; a decrease or increase in the resistance of the right axillary artery may lead to brain malperfusion (36). Hence, brain blood flow and oxygen consumption should be monitored by Transcranial Doppler ultrasonography (TCD) and near-infrared spectroscopy during the Anterograde perfusion technique (ACP). Also, IAC is not recommended for patients with the following conditions: second surgery, innominate artery dissection, or calcification (37).

\section{Femoral artery cannulation (FAC)}

As CPB can be rapidly set up through FAC, FAC is extremely suitable for AAD patients with hemodynamic instability. Compared with other cannulation methods, FAC can improve renal perfusion and decrease the risk of renal impairment after surgery (38). To a certain extent, if the renal artery is involved by dissection before surgery, then FAC should be adopted. The FAC's biggest challenge is organ malperfusion that is caused due to false lumen perfusion and stroke resulting from plaque shedding during retrograde perfusion. Comparative studies have shown the association of FAC with higher mortality and stroke rates than axillary artery cannulation (39). In particular, the femoral artery is not an ideal cannulation site when severe atherosclerosis is observed in the thoracoabdominal aorta, iliofemoral system, and the femoral artery with an extended dissection flap (40). Therefore, FAC reduces complications by the femoral artery ultrasonic examination before the surgery (41). Also, FAC could lead to distal malperfusion due to cannula obstruction. Hence, the cannula's size should be smaller than the vessel's diameter to ensure blood supply to the distal extremities. 
Although the FAC-associated complications can be controlled at a low level by close monitoring, insufficient perfusion of organs is inevitable. Moreover, the clinical symptoms associated with insufficient perfusion in the spinal cord, mesentery, kidney, and other parts of the body are difficult to determine during the operation. Hence, the femoral artery, combined with another artery perfusion, is the preferred solution (42).

Knowing how to identify the cannula into the false lumen is essential during FAC. The pump pressure would suddenly increase after pumping 50 100 $\mathrm{ml}$ liquid, or the pump pressure would keep rising when $\mathrm{CPB}$ is initiated. Malperfusion could be identified via the bilateral radial artery pressure and an abnormal drop in the cerebral oxygen value. When malperfusion occurs below the diaphragm level, the urine volume is significantly reduced during CPB. To address malperfusion caused by cannulation entering the false lumen. FAC cannulation was guided by the TEE Seldinger technique or combined with axillary cannulation $(40,43)$. Further, the true lumen's blood supply may be determined using color Doppler; however, its implementation in clinical practice is difficult due to technical inconvenience.

\section{Right axillary artery cannulation (RAAC)}

Dissection, arteriosclerosis and plaque are rarely involved in the axillary artery. Although axillary artery cannulation is relatively time consuming and carries the risk of vascular and nerve injury, it continues to be an appropriate choice due to its good cerebral protection effect and antegrade perfusion $(44,45)$. Indeed, the 2014 ESC guidelines recommended RAAC as the preferred site for AAD (46). However, Imanaka et al. (47) reported that RAAC could lead to circumferential dissection at the bifurcation of the innominate artery near the right carotid and subclavian arteries, without any pressure on the right radial artery after the surgery. Therefore, it is crucial to monitor arterial pressure changes (left and right radial artery pressures, femoral artery pressure) during the operation to prevent adverse events when RAAC is used. Rokkas et al. (48) published a case report on acute intraoperative aortic dissection, wherein the ascending aorta and the aortic arch were dissected. The innominate artery was dissected, including one-third of its circumference anteriorly following AAC. CPB was at once paused, and left femoral artery cannulation was set up to resume CPB.

In most ADD patients, left axillary cannulation was usually not preferred and unnecessary $(49,50)$. However, left axillary artery perfusion is essential for posterior brain perfusion in some patients, such as left vertebral arteries dominance lead to malperfusion (i.e., reducing $\mathrm{rSO}_{2}$ ) during antegrade selective cerebral perfusion (51). Therefore, it is important to confirm the laterality and contribution of the left and right vertebral arteries before surgery via CTA.

RAAC includes direct cannulation or side graft. Although the side vascular graft is time consuming and technically demanding, it can avoid the limited flow rate associated with the direct cannulation (52). RAAC does not cause distal limb ischemia; however, it can cause distal limb hyperperfusion syndrome. When the subclavian artery participates in the dissection, cannulation of the axillary artery may lead to retrograde carotid dissection and cerebral malperfusion (53).

When direct cannulation is complex, the side graft is preferred to reduce artery and brachial plexus injuries. The treatment after decannulation is simple and does not require repairing the cannulation incision. Therefore, the occurrence of axillary artery stenosis can be avoided. The factors that affect RAAC include hemodynamic instability, dissection or vascular wall thinness, obesity, small vessels, surgical techniques, and personal preferences (54). Owing to the influence of the circle of Willis, unilateral, bilateral, or whole-brain perfusion is selected based on cerebral oxygen or TCD during ACP. RAAC combined with FAC may further improve the brain protection effect (55).

\section{Double arterial cannulation (DAC)}

Various centers prefer DAC instead of using single arterial cannulation (SAC). The innominate artery or axillary artery combined with FAC is used for DAC perfusion. Clinical studies have confirmed that DAC can provide satisfactory cerebral and distal organ protection and avoid deep hypothermia-related side effects $(56,57)$. The greatest advantage of DAC is that the RAAC can make up for the femoral artery-induced false cavity perfusion and that FAC can compensate for the insufficient flow of the RAAC. Lin et al. (58) explained that DAC might achieve better systemic perfusion than SAC through anterograde and retrograde perfusion, especially in dissected branch-vessels containing re-entry tear and compromised true lumen. In other words, DAC can supply more stable systemic perfusion compared to SAC. Hence, DAC is suitable for patients with stable hemodynamic status despite poor preoperative presentation. 
Table 1 Advantages and disadvantage of various cannulations

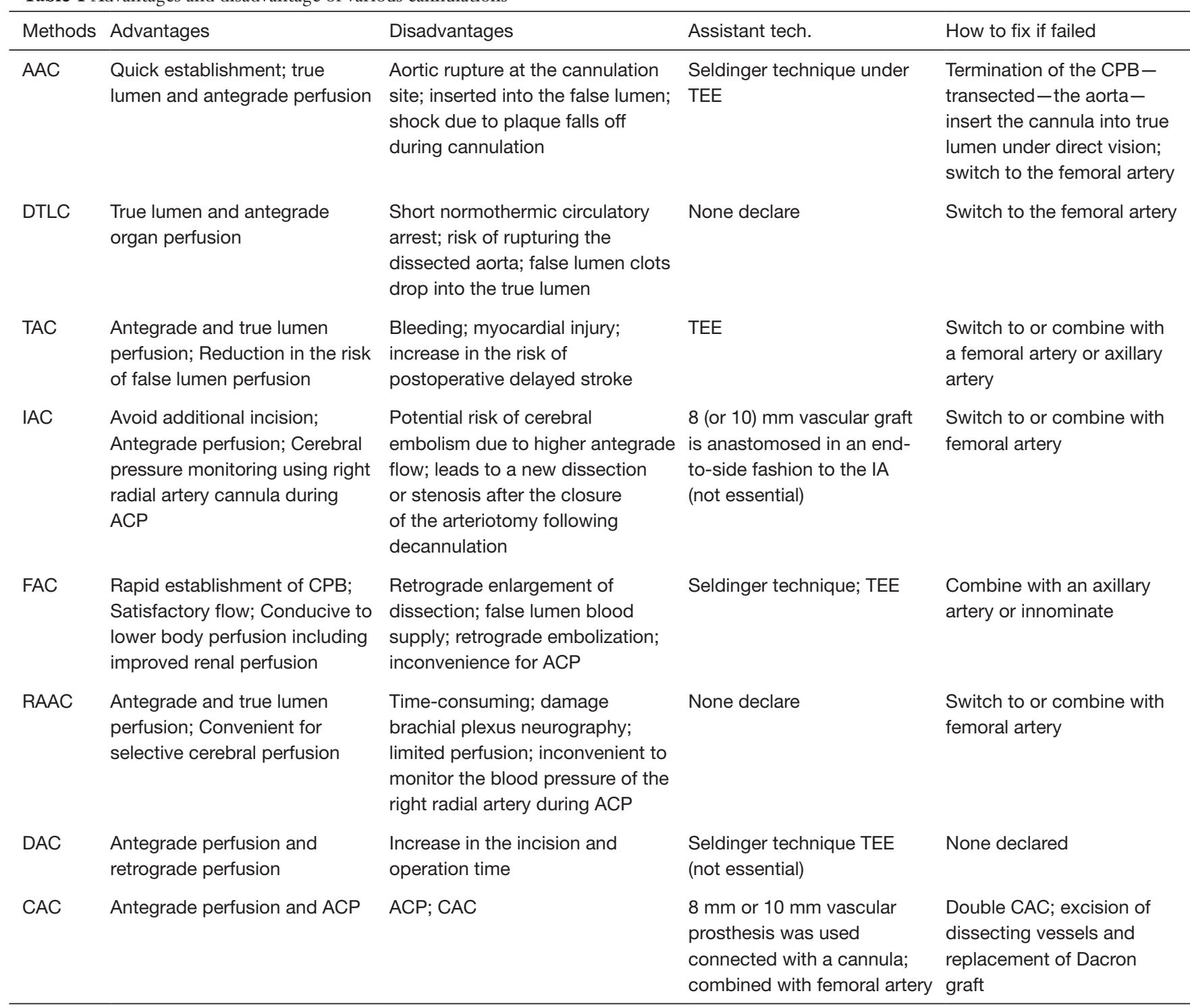

ACP, anterograde cerebral perfusion; CAC, carotid artery cannulation

This is because it can reduce postoperative complications associated with poor perfusion. Thus, DAC is effective for both the prevention and management of intraoperative malperfusion (56). In order to better understand, we had made some summaries in Table 1 .

\section{Cannulation strategy of dissection involved in the carotid artery}

Unilateral, bilateral, partial, and circumferential dissection of the carotid artery is not acceptable as it results in the true narrow lumen and clinical signs of cerebral malperfusion. It is therefore essential to deal with this complexity appropriately.

Urbanski et al. $(59,60)$ reported that the left CCA cannulation combined with FAC was used in special circumstances, in which the innominate and carotid arteries showed severe compression of the true lumen by the false lumen. A $10 \mathrm{~mm}$ Dacron side graft was connected with a cannula in the left carotid artery and a flow of $0.8-1.0 \mathrm{~L} / \mathrm{min}$ for ACP. They showed that the $\mathrm{CCA}$, as a standard procedure, was an excellent cannulation 
site in AAD. They also discussed a case with AAD having signs of malperfusion wherein proximal aortic repair with CAC could have favorable surgical outcomes. In short, they believed that this surgical access was easy and quick and, therefore, suitable for emergencies. In cases with compression of the true lumen in both the carotid arteries and malperfusion before surgery, CCA cannulation ensures unilateral unrestricted cerebral perfusion during $\mathrm{CPB}$ and ACP. Consistent with the above observation, Dr. Bachet's (61) positive opinion of this technique and supporting its wide application was extremely motivating.

It is difficult to deal with carotid circumferential or almost circumferential dissection in the innominate and the common carotid arteries. Urbanski et al. (62) suggested a solution to this problem. First, the $\mathrm{CPB}$ was set up through FAC combined with the left CCA, and the temperature was brought to $28^{\circ} \mathrm{C}$. Second, the CCA with dissection was resected, and an 8-mm-wide Dacron graft was replaced. Third, the side graft was connected to the interposition graft end-to-side, followed by a connection to the bifurcated arterial line's second arm to ensure sufficient cerebral perfusion during $\mathrm{CPB}$ and $\mathrm{ACP}$.

It should be noted that combined FAC perfusion is necessary for complex cases. Also, Okita et al. (63) reported a successful strategy for the right carotid artery's reperfusion before surgery in patients with preoperative brain malperfusion due to aortic dissection. This technique effectively improved blood flow to the brain prior to the surgery and helped patients recover from the effects of the surgery. An important part of this reperfusion technology involved setting up a simple bypass circuit between the common femoral artery and the right CCA. The reperfusion path can be described as follows: right common femoral artery (14-Fr double-lumen cannula)—small roller pump (a blood flow of 4-6 $\mathrm{mL} / \mathrm{kg} / \mathrm{min}$ ) - heat exchanger coil $\left(30^{\circ} \mathrm{C}\right)$-right CCA $(12$-Fr pediatric arterial cannula).

\section{Penza cannulation}

Rosseykin et al. (64) reported a new cannulation technique called "Penza cannulation." This is double artery perfusion, which included two steps: (I) the cannula was inserted into the true lumen of descending aorta via the left subclavian artery; and (II) the left subclavian artery, left CCA, and the brachiocephalic artery was replaced using a trifurcation graft with an added perfusion side-arm ("branch first" technique). ACP was resumed from the side-arm of the trifurcation graft. Although this study suggested that this method was simple, effective, and safe, and may be used as an alternative method in $\mathrm{AAD}$, specific anatomical lesions, which would be more suitable for this method, were not mentioned.

\section{Cannulation strategy in anatomical variations aortic arch branches}

The presence of congenital anomalies of the aortic arch in AAD patients could not be ignored $(65,66)$, and special cerebral perfusion strategies need to be considered based on different situations. Mogi et al. (67) shared their experience in dealing with the aberrant right subclavian artery and isolated left vertebral artery in AAD. They suggested that the isolated left vertebral artery be removed from the aortic arch, and reconstruction should be performed to improve brain perfusion during ACP. Maxwell et al. (68) described the monitoring, perfusion strategy, and surgical technique used in patients with congenital anomalies of the aortic arch. The aberrant right subclavian artery does not allow RAAC with monitoring of the left upper extremity arterial pressure. The management of "bovine" arch patterns during ACP requires clamping above or below the takeoff of the left CCA, resulting in unilateral or bilateral antegrade cerebral perfusion. Managing patients with a right arch is different from that of normal anatomy (for patients who have traditional mirror-image branching) or that of the aberrant right subclavian group (for patients who have a corresponding aberrant left subclavian artery).

\section{Cannulation strategy For AAD patients with anatomical variations of the cerebrovascular}

The variation, malformation, dysplasia, and other cerebrovascular problems need special attention in certain AAD cases $(69,70)$. Most studies concerned the circle of Willis (Circle) variants and the vertebral artery dysplasia (i.e., small, thin, and missing artery) (70-72). Although there was a debate on whether Willis' circle is correlated with insufficient brain perfusion during ACP $(70,73)$, considering the risk of insufficient cerebral perfusion during ACP, double/whole cerebral perfusion should be individually adopted.

\section{Cerebral protective perfusion technique and intraperitoneal organ protective perfusion technique}

$\mathrm{ACP}$ and retrograde cerebral perfusion (RCP) is the most 
commonly used cerebral protective perfusion technique (74-76). ACP can either be unilateral cerebral perfusion or bilateral cerebral perfusion and whole brain perfusion (77). According to the literature even at higher temperatures $\left(24-28^{\circ} \mathrm{C}\right)$, unilateral perfusion is sufficient for short-term (<40 min) selective ACP (78). However, for long-term selective ACP, bilateral selective ACP shows improved brain protection (79). In addition, another significant factor that affects bilateral cerebral perfusion is the integrity of the Wills ring (80). Some data support the superiority of bilateral SCP over bilateral selective ACP, because most of the variations reported do not have haemodynamic significance during bilateral SCP (73). As the integrity of Wills ring is not the only decisive factor for bilateral cerebral perfusion, several authors have suggested the establishment of a comprehensive judgment on the basis of intraoperative monitoring results, such as $\mathrm{rSO}_{2}, \mathrm{TCD}$, electroencephalograph (EEG), preoperative cerebral angiography and/or brain computerized tomography $(70,81)$.

It was noteworthy that Lin et al. (82) reported a novel perfusion method named ACP combined with retrograde inferior vena caval perfusion (RIVP). In short, two separate perfusion pumps were used during ACP, pump 1 for ACP and pump 2 for RIVP. The perfusion flow of pump 1 was maintained at 6 to $12 \mathrm{~mL} \cdot \mathrm{min}^{-1} \cdot \mathrm{kg}^{-1}$ to keep $\mathrm{rSO}_{2}$ within $\pm 10 \%$ of baseline. Pump 2 pressure was supported at 20 to $30 \mathrm{mmHg}$, and blood flow was supported at 8 to $12 \mathrm{~mL} \cdot \mathrm{min}^{-1} \mathrm{~kg}^{-1}$. Oxygenated blood flow in the liver and kidney was observed under TEE. This method terminated the history of no blood perfusion in the abdominal organs during conventional ACP and was greatly beneficial for liver and kidney and other viscera protection. Although this approach's results are not fully proven, a multicenter clinical trial is underway, and we expect to see outcomes from this clinical trial (83).

\section{Monitoring}

\section{Significance of TCD monitoring}

During selective ACP, TCD can monitor the blood flow to the brain and assess cerebral perfusion (84). However, it can be troublesome to operate TCD due to excessive labor consumption and constant monitoring. Further, the utility and flexibility of TCD are inferior to that of $\mathrm{rSO}_{2}$.

\section{Significance of cerebral oxygen saturation monitoring}

Cerebral oxygen monitoring is necessary for AAD surgery to prevent focal neurologic deficit (85). Therefore, the monitoring is accurate and convenient and has more clinical application value than TCD $(84,86)$. When the numeric value of $\mathrm{rSO}_{2}$ is lesser than $20 \%$ of the baseline value or an absolute value of 50, insufficient cerebral perfusion needs to be carefully identified (87); therefore, effective measures, such as the appropriate increase of $\mathrm{CO}_{2}$, maintaining blood flow and blood pressure, adjusting the position of cannulation or adding bilateral/global brain perfusion, need to be adopted to improve brain perfusion (88). Also, other assisting approaches, including using a balloon-tip cannula inserted into the left carotid artery (89), direct external clamping of the left carotid artery near its origin from the aortic arch, and application of external pressure with the ultrasound probe to partially compress the left carotid artery, will reduce the carotid "steal" phenomenon and increase $\mathrm{rSO}_{2}(90)$.

\section{Significance of arterial pressure monitoring}

Pressure monitoring in both the radial arteries and bilateral cerebral oxygen saturation measurement helps identify malperfusion after establishing CPB (91). The blood pressure of the femoral and radial arteries is monitored at routine intervals. Simultaneously, attention needs to be paid to the lowest blood pressure of the femoral and left and right radial arteries before, during, and post-operation. Radial arterial contracture affects the blood pressure, and the recovery of postoperative femoral artery pressure also shows the correction of the false lumen, which is caused by aortic dissection (92). It should be noted that if RAAC is directly used without side graft, the right radial artery pressure might be disturbed. Hence, the radial artery's true pressure needs to be determined by aortic root pressure measurement or cuff method of manometry.

\section{Conclusions}

The arterial cannulation site and strategy should be determined individually. The ideal AAD cannulation strategy aims to set up quick and satisfactory perfusion flow, minimize any organ malperfusion, prevent further expansion of dissection or aortic rupture, and supply optimal brain protection when ACP is needed. The selection of the right cannulation method is dependent on the vascular condition, hemodynamic of the patient, surgical technique, and preference of the surgeon. Each cannulation has its advantages and disadvantages, which 
should be carefully weighed before surgery. DAC is the most recommended because it can supply a double and combined blood perfusion model.

It should be noted that none of the cannulation strategies are perfect for all AAD. Preoperative and intraoperative malperfusion, especially CPB-related malperfusion of the brain or malperfusion caused by cannulation, must be identified using different CTA methods, arterial pressure change, TEE, TCD, and cerebral oximetry monitoring.

For patients' intraoperative brain protection, irrespective of the method used, the most important thing is to support the proper blood flow and oxygen consumption ratio during ACP. The best way to achieve this goal is to monitor the brain perfusion state by measuring both TCD and $\mathrm{rSO}_{2}$ during ACP.

Of note is that ACP combined with RIVP may become a popular perfusion method due to its possible abdominal organ protection.

\section{Acknowledgments}

Funding: Medical Scientific Research Foundation of Guangdong Province in China (No. A2021241). Natural Science Foundation of Liaoning Province (20180550183).

\section{Footnote}

Reporting Checklist: The authors have completed the Narrative Review reporting checklist. Available at http:// dx.doi.org/10.21037/jtd-21-411

Conflicts of Interest: All authors have completed the ICMJE uniform disclosure form (available at http://dx.doi. org/10.21037/jtd-21-411). The authors have no conflicts of interest to declare.

Ethical Statement: The authors are accountable for all aspects of the work in ensuring that questions related to the accuracy or integrity of any part of the work are appropriately investigated and resolved. All personal data have been protected and secured according to current national and international laws.

Open Access Statement: This is an Open Access article distributed in accordance with the Creative Commons Attribution-NonCommercial-NoDerivs 4.0 International License (CC BY-NC-ND 4.0), which permits the non- commercial replication and distribution of the article with the strict proviso that no changes or edits are made and the original work is properly cited (including links to both the formal publication through the relevant DOI and the license). See: https://creativecommons.org/licenses/by-nc-nd/4.0/.

\section{References}

1. Tchana-Sato V, Sakalihasan N, Defraigne JO. Aortic dissection. Rev Med Liege 2018;73:290-5.

2. Almdahl SM. An alternative technique for cannulation in type A dissection. Eur J Cardiothorac Surg 2015;48:339.

3. Abe T, Usui A. The cannulation strategy in surgery for acute type A dissection. Gen Thorac Cardiovasc Surg 2017;65:1-9.

4. Speir AM. Commentary: Cannulation alternatives for acute type I aortic dissection: Does this constitute a conundrum. J Thorac Cardiovasc Surg 2019;158:35-6.

5. Kreibich $M$, Chen Z, Rylski B, et al. Outcome after aortic, axillary, or femoral cannulation for acute type A aortic dissection. J Thorac Cardiovasc Surg 2019;158:27-34.e9.

6. Osumi M, Wada H, Morita Y, et al. Safety and efficacy of ascending aorta cannulation during repair of acute type $\mathrm{A}$ aortic dissection (PA29-04): "Presented at the 65th Annual Scientific Meeting of the Japanese Association for Thoracic Surgery". Gen Thorac Cardiovasc Surg 2014;62:296-300.

7. Tiwari KK, Murzi M, Bevilacqua S, et al. Which cannulation (ascending aortic cannulation or peripheral arterial cannulation) is better for acute type A aortic dissection surgery. Interact Cardiovasc Thorac Surg 2010;10:797-802.

8. Frederick JR, Yang E, Trubelja A, et al. Ascending aortic cannulation in acute type a dissection repair. Ann Thorac Surg 2013;95:1808-11.

9. Ma H, Xiao Z, Shi J, et al. Aortic arch cannulation with the guidance of transesophageal echocardiography for Stanford type A aortic dissection. J Cardiothorac Surg 2018;13:106.

10. Taguchi S, Mori A, Suzuki R, et al. Simplicity, skills, and pitfalls of ascending aortic cannulation for type A aortic dissection. J Cardiothorac Surg 2013;8:161.

11. Khoynezhad A, Plestis KA. Cannulation in the diseased aorta: a safe approach using the Seldinger technique. Tex Heart Inst J 2006;33:353-5.

12. Reece TB, Tribble CG, Smith RL, et al. Central cannulation is safe in acute aortic dissection repair. J Thorac Cardiovasc Surg 2007;133:428-34. 
13. Kitamura T, Nie M, Horai T, et al. Direct True Lumen Cannulation ("Samurai" Cannulation) for Acute Stanford Type A Aortic Dissection. Ann Thorac Surg 2017;104:e459-61.

14. Khaladj N, Shrestha M, Peterss S, et al. Ascending aortic cannulation in acute aortic dissection type A: the Hannover experience. Eur J Cardiothorac Surg 2008;34:792-6; disussion 796.

15. Kamiya H, Kallenbach K, Halmer D, et al. Comparison of ascending aorta versus femoral artery cannulation for acute aortic dissection type A. Circulation 2009;120:S282-6.

16. Boldyrev SY, Polyahova AA, Barbukhatty KO, et al. Direct True Lumen Cannulation for Acute Type A Aortic Dissection. Ann Thorac Surg 2019;107:984.

17. Jakob H, Tsagakis K, Szabo A, et al. Rapid and safe direct cannulation of the true lumen of the ascending aorta in acute type A aortic dissection. J Thorac Cardiovasc Surg 2007;134:244-5

18. Sosnowski AW, Jutley RS, Masala N, Alexiou C, Swanevelder J. How I do it: transapical cannulation for acute type-A aortic dissection. J Cardiothorac Surg 2008;3:4.

19. Kise Y, Kuniyoshi Y, Ando M, et al. Transapical aortic perfusion using a deep hypothermic procedure during descending thoracic or thoracoabdominal aortic surgery. J Cardiovasc Surg (Torino) 2019;60:749-54.

20. Suenaga E, Sato M, Fumoto H, et al. Impact of transapical aortic cannulation for acute type A aortic dissection. Ann Thorac Cardiovasc Surg 2015;21:382-7.

21. Djukanovic BP, Micovic S, Peric MS, et al. The role of transapical cannulation in the operative management of acute aortic dissection. Perfusion 2015;30:332-6.

22. Terasaki T, Takano T, Fujii T, et al. Early and midterm results of transapical and right axillary artery cannulation for acute aortic dissection. J Cardiothorac Surg 2015;10:2.

23. Matsushita A, Manabe S, Tabata M, et al. Efficacy and pitfalls of transapical cannulation for the repair of acute type A aortic dissection. Ann Thorac Surg 2012;93:1905-9.

24. Shimamura J, Yamamoto S, Oshima S, et al. Surgical outcomes of aortic repair via transapical cannulation and the adventitial inversion technique for acute Type A aortic dissection. Eur J Cardiothorac Surg 2018;54:369-74.

25. Yamamoto S, Hosoda Y, Yamasaki M, et al. Transapical aortic cannulation for acute aortic dissection to prevent malperfusion and cerebral complications. Tex Heart Inst J 2001;28:42-3.

26. Jutley RS, Masala N, Sosnowski AW. Transapical aortic cannulation: the technique of choice for type A dissection. J Thorac Cardiovasc Surg 2007;133:1393-4; author reply 1394.

27. Fukuda I, Aikawa S, Imazuru T, et al. Transapical aortic cannulation for acute aortic dissection with diffuse atherosclerosis. J Thorac Cardiovasc Surg 2002;123:369-70.

28. Wada S, Yamamoto S, Honda J, et al. Transapical aortic cannulation in the operation of acute type A aortic dissection. Kyobu Geka 2007;60:315-8.

29. Augoustides JG. Limitations with transapical aortic cannulation in type A aortic dissection: what about aortic regurgitation and cardiopulmonary bypass time? J Thorac Cardiovasc Surg 2007;133:1393; author reply 1393.

30. Eldeiry M, Ghincea C, Aftab M, et al. Innominate Versus Axillary Artery Cannulation for the Hemiarch Repair. J Surg Res 2018;232:234-9.

31. Augoustides JG, Harris H, Pochettino A. Direct innominate artery cannulation in acute type a dissection and severe thoracic aortic atheroma. J Cardiothorac Vasc Anesth 2007;21:727-9.

32. Harky A, Wong C, Chan J, et al. Innominate artery cannulation in aortic surgery: A systematic review. J Card Surg 2018;33:818-25.

33. Berretta P, Alfonsi J, Di Bartolomeo R, et al. Innominate artery cannulation during aortic surgery. Multimed Man Cardiothorac Surg 2015;2015:mmv030.

34. Huang FJ, Wu Q, Ren CW, et al. Cannulation of the innominate artery with a side graft in arch surgery. Ann Thorac Surg 2010;89:800-3.

35. Hosseini S, Rezaei Y, Motevalli M, et al. Suprasternal innominate artery cannulation for reoperative aortic surgery: a technical note. Interact Cardiovasc Thorac Surg 2016;23:832-4.

36. Ji B, Liu J, Chang Q, et al. Benefits and risks with using cannulation at the innominate artery with a side graft during arch surgery. Ann Thorac Surg 2011;91:1649-50; author reply 1650.

37. Di Eusanio M, Ciano M, Labriola G, et al. Cannulation of the innominate artery during surgery of the thoracic aorta: our experience in 55 patients. Eur J Cardiothorac Surg 2007;32:270-3.

38. Ram E, Krupik Y, Lipey A, et al. Is Axillary Better Than Femoral Artery Cannulation in Repair of Acute Type A Aortic Dissection. Innovations (Phila) 2019;14:124-33.

39. Peterson MD, Mazine A, El-Hamamsy I, et al. Knowledge, attitudes, and practice preferences of Canadian cardiac surgeons toward the management of acute type A aortic dissection. J Thorac Cardiovasc Surg 2015;150:824-31.e1-5. 
40. Tsiouris A, Elkinany S, Ziganshin BA, et al. Open Seldinger-Guided Femoral Artery Cannulation Technique for Thoracic Aortic Surgery. Ann Thorac Surg 2016;101:2231-5.

41. Lee HK, Kim GJ, Cho JY, et al. Comparison of the Outcomes between Axillary and Femoral Artery Cannulation for Acute Type A Aortic Dissection. Korean J Thorac Cardiovasc Surg 2012;45:85-90.

42. Pacini D, Leone A, Belotti LM, et al. Acute type A aortic dissection: significance of multiorgan malperfusion. Eur J Cardiothorac Surg 2013;43:820-6.

43. Pavlisko ND, Soares J, Henao-Guerrero NP, et al. Ultrasound-guided catheterization of the femoral artery in a canine model of acute hemorrhagic shock. J Vet Emerg Crit Care (San Antonio) 2018;28:579-84.

44. Wong DR, Coselli JS, Palmero L, et al. Axillary artery cannulation in surgery for acute or subacute ascending aortic dissections. Ann Thorac Surg 2010;90:731-7.

45. Benedetto U, Mohamed H, Vitulli P, et al. Axillary versus femoral arterial cannulation in type A acute aortic dissection: evidence from a meta-analysis of comparative studies and adjusted risk estimates. Eur J Cardiothorac Surg 2015;48:953-9.

46. Erbel R, Aboyans V, Boileau C, et al. 2014 ESC Guidelines on the diagnosis and treatment of aortic diseases:

Document covering acute and chronic aortic diseases of the thoracic and abdominal aorta of the adult. The Task Force for the Diagnosis and Treatment of Aortic Diseases of the European Society of Cardiology (ESC). Eur Heart J 2014;35:2873-926.

47. Imanaka K, Kyo S, Tanabe H, et al. Fatal intraoperative dissection of the innominate artery due to perfusion through the right axillary artery. J Thorac Cardiovasc Surg 2000;120:405-6.

48. Rokkas CK, Angouras D, Chamogeorgakis T, et al. Acute intraoperative aortic dissection following axillary artery cannulation. Interact Cardiovasc Thorac Surg 2008;7:288-9.

49. Neri E, Massetti M, Capannini G, et al. Axillary artery cannulation in type a aortic dissection operations. J Thorac Cardiovasc Surg 1999;118:324-9.

50. Rylski B, Czerny M, Beyersdorf F, et al. Is right axillary artery cannulation safe in type A aortic dissection with involvement of the innominate artery. J Thorac Cardiovasc Surg 2016;152:801-7.e1.

51. Orihashi K, Sueda T, Okada K, et al. Detection and monitoring of complications associated with femoral or axillary arterial cannulation for surgical repair of aortic dissection. J Cardiothorac Vasc Anesth 2006;20:20-5.
52. Preventza O, Price MD, Spiliotopoulos K, et al. In elective arch surgery with circulatory arrest, does the arterial cannulation site really matter? A propensity score analysis of right axillary and innominate artery cannulation. J Thorac Cardiovasc Surg 2018;155:1953-60.e4.

53. Moizumi Y, Motoyoshi N, Sakuma K, et al. Axillary artery cannulation improves operative results for acute type a aortic dissection. Ann Thorac Surg 2005;80:77-83.

54. Rosinski BF, Idrees JJ, Roselli EE, et al. Cannulation strategies in acute type A dissection repair: A systematic axillary artery approach. J Thorac Cardiovasc Surg 2019;158:647-59.e5.

55. Manetta F, Mullan CW, Catalano MA. Neuroprotective Strategies in Repair and Replacement of the Aortic Arch. Int J Angiol 2018;27:98-109.

56. Kusadokoro S, Kimura N, Hori D, et al. Utility of double arterial cannulation for surgical repair of acute type A dissection. Eur J Cardiothorac Surg 2020;57:1068-75.

57. Guo J, Wang Y, Zhu J, et al. Right axillary and femoral artery perfusion with mild hypothermia for aortic arch replacement. J Cardiothorac Surg 2014;9:94.

58. Lin CY, Tseng CN, Lee HA, et al. Double arterial cannulation strategy for acute type A aortic dissection repair: A 10-year single-institution experience. PLoS One 2019; 14:e0211900.

59. Urbanski PP. Carotid artery cannulation in acute aortic dissection with malperfusion. J Thorac Cardiovasc Surg 2006;131:1398-9.

60. Urbanski PP, Lenos A, Lindemann Y, et al. Carotid artery cannulation in aortic surgery. J Thorac Cardiovasc Surg 2006;132:1398-403.

61. Bachet J. Carotid artery cannulation in aortic surgery: why not? Multimed Man Cardiothorac Surg 2015;2015:mmv028.

62. Urbanski PP, Irimie V, Wagner M. Cannulation and perfusion strategy in acute aortic dissection involving both common carotid arteries. Interact Cardiovasc Thorac Surg 2015;21:557-9.

63. Okita Y, Matsumori M, Kano H. Direct reperfusion of the right common carotid artery prior to cardiopulmonary bypass in patients with brain malperfusion complicated with acute aortic dissection. Eur J Cardiothorac Surg 2016;49:1282-4.

64. Rosseykin E, Kobzev E, Bazylev V. One more method for arterial cannulation in aortic arch surgery ("Penza cannulation"). Asian Cardiovasc Thorac Ann 2018;26:584-6.

65. Ikeno Y, Koide Y, Matsueda T, et al. Anatomical variations of aortic arch vessels in Japanese patients with aortic arch 
disease. Gen Thorac Cardiovasc Surg 2019;67:219-26.

66. Qiu Y, Wu X, Zhuang Z, et al. Anatomical variations of the aortic arch branches in a sample of Chinese cadavers: embryological basis and literature review. Interact Cardiovasc Thorac Surg 2019;28:622-8.

67. Mogi K, Okimoto M, Okada Y. Emergent ascending and arch replacement for acute type A aortic dissection with anomalies of the aortic arch. Kyobu Geka 2003;56:817-21; discussion 821-4.

68. Maxwell BG, Harrington KB, Beygui RE, et al. Congenital anomalies of the aortic arch in acute type-a aortic dissection: implications for monitoring, perfusion strategy, and surgical repair. J Cardiothorac Vasc Anesth 2014;28:467-72.

69. Sugiura T, Imoto K, Uchida K, et al. Evaluation of the vertebrobasilar system in thoracic aortic surgery. Ann Thorac Surg 2011;92:568-70.

70. Papantchev V, Hristov S, Todorova D, et al. Some variations of the circle of Willis, important for cerebral protection in aortic surgery--a study in Eastern Europeans. Eur J Cardiothorac Surg 2007;31:982-9.

71. Ghazy T, Darwisch A, Schmidt T, et al. The Transcranial Doppler Sonography for Optimal Monitoring and Optimization of Cerebral Perfusion in Aortic Arch Surgery: A Case Series. Heart Surg Forum 2017;20:E085-8.

72. Qi R, Sun L, Zhu J, et al. Total arch replacement in patients with aortic dissection with an isolated left vertebral artery. Ann Thorac Surg 2013;95:36-40.

73. Papantchev V, Stoinova V, Aleksandrov A, et al. The role of Willis circle variations during unilateral selective cerebral perfusion: a study of 500 circles. Eur J Cardiothorac Surg 2013;44:743-53.

74. van den Brule JMD, van der Hoeven JG, Hoedemaekers CWE. Cerebral Perfusion and Cerebral Autoregulation after Cardiac Arrest. Biomed Res Int 2018;2018:4143636.

75. Tian DH, Weller J, Hasmat S, et al. Adjunct retrograde cerebral perfusion provides superior outcomes compared with hypothermic circulatory arrest alone: A meta-analysis. J Thorac Cardiovasc Surg 2018;156:1339-48.e7.

76. Ueda Y. Retrograde cerebral perfusion still remains a valuable adjunct for hypothermic circulatory arrest. J Thorac Cardiovasc Surg 2018;156:1337-8.

77. Foley LS, Yamanaka K, Reece TB. Arterial Cannulation and Cerebral Perfusion Strategies for Aortic Arch Operations. Semin Cardiothorac Vasc Anesth 2016;20:298-302.

78. Spielvogel D, Kai M, Tang GH, et al. Selective cerebral perfusion: a review of the evidence. J Thorac Cardiovasc Surg 2013;145:S59-62.
79. Malvindi PG, Scrascia G, Vitale N. Is unilateral antegrade cerebral perfusion equivalent to bilateral cerebral perfusion for patients undergoing aortic arch surgery. Interact Cardiovasc Thorac Surg 2008;7:891-7.

80. Jin ZN, Dong WT, Cai XW, et al. CTA Characteristics of the Circle of Willis and Intracranial Aneurysm in a Chinese Crowd with Family History of Stroke. Biomed Res Int 2016;2016:1743794.

81. Urbanski PP, Lenos A, Blume JC, et al. Does anatomical completeness of the circle of Willis correlate with sufficient cross-perfusion during unilateral cerebral perfusion. Eur J Cardiothorac Surg 2008;33:402-8.

82. Lin J, Xiong J, Luo M, et al. Combining Cerebral Perfusion With Retrograde Inferior Vena Caval Perfusion for Aortic Arch Surgery. Ann Thorac Surg 2019;107:e67-9.

83. Lin J, Tan Z, Yao H, et al. Retrograde Inferior Vena caval Perfusion for Total Aortic arch Replacement Surgery (RIVP-TARS): study protocol for a multicenter, randomized controlled trial. Trials 2019;20:232.

84. Wang X, Ji B, Yang B, et al. Real-time continuous neuromonitoring combines transcranial cerebral Doppler with near-infrared spectroscopy cerebral oxygen saturation during total aortic arch replacement procedure: a pilot study. ASAIO J 2012;58:122-6.

85. Vranken NPA, Weerwind PW, Sutedja NA, et al. Cerebral Oximetry and Autoregulation during Cardiopulmonary Bypass: A Review. J Extra Corpor Technol 2017;49:182-91.

86. Yu Y, Lyu Y, Jin L, et al. Prognostic factors for permanent neurological dysfunction after total aortic arch replacement with regional cerebral oxygen saturation monitoring. Brain Behav 2019;9:e01309.

87. Harrer M, Waldenberger FR, Weiss G, et al. Aortic arch surgery using bilateral antegrade selective cerebral perfusion in combination with near-infrared spectroscopy. Eur J Cardiothorac Surg 2010;38:561-7.

88. Li B, Hu X, Wang Z. The neurologic protection of unilateral versus bilateral antegrade cerebral perfusion in aortic arch surgery with deep hypothermic circulatory arrest: A study of 77 cases. Int J Surg 2017;40:8-13.

89. Chan SK, Underwood MJ, Ho AM, et al. Cannula malposition during antegrade cerebral perfusion for aortic surgery: role of cerebral oximetry. Can J Anaesth 2014;61:736-40.

90. Grocott HP, Ambrose E, Moon M. External carotid compression: a novel technique to improve cerebral perfusion during selective antegrade cerebral perfusion for aortic arch surgery. Can J Anaesth 2016;63:1179-83.

91. Caldas JR, Haunton VJ, Panerai RB, et al. Cerebral 
autoregulation in cardiopulmonary bypass surgery: a systematic review. Interact Cardiovasc Thorac Surg 2018;26:494-503.

92. Shimokawa T, Takanashi S, Ozawa N, et al. Management of intraoperative malperfusion syndrome using femoral

Cite this article as: Xia Q, Cao Y, Xie B, Qiu D, Deng L, Wang M, Han H. Cannulation strategies in type A aortic dissection: a novel insight narrative review. J Thorac Dis 2021;13(4):2551-2562. doi: 10.21037/jtd-21-411 artery cannulation for repair of acute type A aortic dissection. Ann Thorac Surg 2008;85:1619-24.

(English Language Editor: J. Chapnick) 